\title{
A Sensitivity Analysis of Water Absorption Parameters of Theobroma Cacao L. Reinforced Epoxy Composites
}

\author{
Chris Abiodun Ayanladun, Sunday Ayoola Oke* \\ Department of Mechanical Engineering, University of Lagos, Lagos, Nigeria
}

\begin{abstract}
Cocoa pod husk composites for structural applications face a substantial water absorption problem in which the residual tensile, fatigue and flexural characteristics always exhibit instant deterioration after immersion in water. Unfortunately, there is an absence of sensitivity analysis research on the composite's water absorption parameters to establish the crucial parameters that may function as drawbacks. Consequently, this study establishes how the sensitivity analysis of the Fickian's model parameters can be measured using single and joint parametric variations in the water absorbed at saturation, interactive indicator and the response indicator between patterns using experimental data and literature sources. Results revealed that the most sensitive case study was obtained when the response indicator between patterns was varied with the absorbed quantity in time, accounting for $95.24 \%$ (20 out of 21 cases). Accordingly, composite engineers and designers should use the most sensitive parameter to control design features.
\end{abstract}

Keywords: Biocomposite, Particle-reinforcement, Polymer-matrix composites (PMCs), Natural fibres

\section{Introduction}

Water absorption in composites is a challenge to users since contacts of composites with water bodies for a long time can cause reduced impact strength, flexural modulus, fracture toughness, flexural strength and hardness [1-4]. Unfortunately, combating this problem through sensitivity analysis of the input and output parameters of the water absorption process in cocoa pod husk composite has not been attempted [515]. Sensitivity analysis assists in establishing the principal parameters that are of significant impacts on the cost reduction effort of water absorption studies in composites [14-15]. Unfortunately, also, the manufacture of composites for water-based environments has failed to establish the principal variables that influence the lifespan of the composite in predictions. This puts the composite engineer in the dark on the crucial variables that require additional information to obtain the optimum lifespan of composites through sensitivity analysis and predictions. Without due studies on sensitivity analysis of cocoa pod husk composite parameters in water absorption, lifespan cannot be predicted, and composite engineers will be unable to focus on pertinent variables. Thus, to have sound predictions and control of water absorption for the cocoa pod husk composite as well as to limit failure costs, composite designers and engineers are required to execute an approach to establish the sensitivity of the water absorption variables in Fickian's

\footnotetext{
* Corresponding author. Tel.: +234-8058179170

E-mail address: sa_oke@yahoo.com

Manuscript History:

Received 06 October, 2020, Revised 20 October, 2020, Accepted 21 October, 2020, Published 30 October, 2020

e-ISSN: 2289-7771

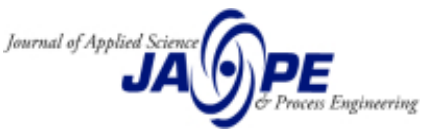


theoretical perspective [4]. This approach assists in understanding the variations in the measurable variables of the water absorption process to establish the possibility of controlling it [4].

Several predictive models on water absorption have been done: Peret et al. [4] examined the moisture absorption of polymeric matrix composites at microscopic and macroscopic scales using numerical homogenization techniques. Several scholars addressed the influence of water absorption on composite and their respective materials experimented upon are stated as Akash et al. [16] studied pulp of Samanea Saman pod (SSP) on moisture uptake of sisal and hemp fibre-reinforced epoxy dual filled composite. Hosseinaei et al. [17] found that water absorption dropped for extracted wood particulates. Anjang et al. [18] studied the influence of moisture absorption on fine resistance or structural pilled composite. Khan et al. [19] fabricated composites with minimized moisture intake by applying farm waste as reinforcement. Ngaowthong et al. [20] examined the influence that re-usage had on moisture intake response of polypropylene-based and naturally decomposable polylactic acid-based composites. Arputhabalan et al. [21] investigated the moisture intake resistance or venal fibre, polymer composites reinforced with glass fibre. Bahra et al. [22] analysed the influence of various proportions of pineapple fibre in pineapple/HDPE composite on moisture response of the composite. Tian and Zhong [23] created a constitutive model following mechanics to analyse the swelling elastic deformation response of organic fibre-reinforced composites. Mishra et al. [24] produced and optimized h-BN composites containing both natural and nonnatural filler. A group of scholars have reduced the water intake of various composites with treatments: Zahari et al. [2] used saline on a polypropylene composite, Rajesh et al. [25] used concentrated $\mathrm{NaOH}$ on jute/polylactic acid composites. Dayo et al. [26] concluded that silane treated fibre composites exhibited the least moisture intake. Devani et al. [27] treated bagasse fibres with $1 \%$ each of sodium hydroxide and acrylic acid to minimise moisture uptake of the resulting composite.

Besides, many application studies have been published on water absorption of composites [23], such as high-end electronics and sensing [19], material recycling [20], mechanical, automobile and marine [28, 29], high performance and lightweight materials [30], heat-insulating materials [24], structural material [16], general-purpose $[2,4,25,26])$. Furthermore, the following types of composites have been made: Particles [19, 24, 28]; short fibres [2, 16, 20, 23, 25, 27, 29, 30].

From the above review of composite literature and discussions, the subject of water absorption quantitative and analysis emerges to be of significant interest to scholars and one that requires further investigations [31-35]. The use of Fickian's theory as a springboard for further research engagements and discussions has been demonstrated in several studies. However, there is no link between reports on Fickian's theory, its application to cocoa pod husk water absorption parameters and sensitivity analysis of the significant parameters in the water absorption process.

To address this deficiency, this paper aims to obtain the sensitivity behaviour of cocoa pod husk epoxy composite of diverse reinforcement percentages in the epoxy matrix. Although some authors worked on cocoa pod husk composite and analysed its water absorption behaviour, no research has been reported on the sensitivity analysis of the Fickian's model concerning this composite. The four principal attributes to the efficient monitoring of composite degradation are the water absorbed at saturation, interactive indicator and the response indicator between patterns.

The highlights of the contributions of this work are : (1) A sensitivity analysis framework is constructed by examining the response of the absorbed water quantity in time while considering the singular and joint variations of the water absorbed at saturation, interactive indicator and the response indicator between patterns in a Fickian model's perspective. Parameters are held varied while others are held constant, and the percentage changes are measured in a novel manner; (2) Cocoa pod husk composite from a local environment in Nigeria has been studied for parametric changes in sensitivity analysis; (3) A range

e-ISSN: $2289-7771$

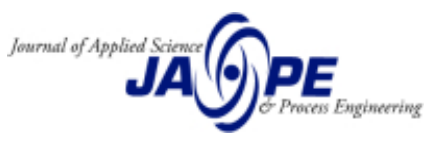


of parameters occurring from 0 to $200 \%$ in steps of $5 \%$ has been documented for the first time in the cocoa pod husk composite literature.

\section{Methods}

\subsection{Preparation of experimental materials}

The cocoa pod husk was sun-dried for days before it was ground into particulates with a Lister grinding machine available for commercial services at Bariga market in Lagos. The ground particulates were sieved into micro-scale using an electric-powered auto sieve shaker A060-01. The diameters of the sieves were $200-250$ - $300-315 \mathrm{~mm}$, and 8", 12". The sieve shaker was initiated by an electric motor and built to contain eight sieves with diameters $200 \mathrm{~mm}$ or seven sieves with a diameter of $300 \mathrm{~mm}$ including the pan and the lid. The design of the timer was to work between 0 and 60 minutes. The power requirement for the sieve was $230 \mathrm{~V} 1 \mathrm{ph} 50 \mathrm{~Hz} 110 \mathrm{~W}$ while the dimensions were $350 \times 400 \times 950 \mathrm{~mm}$ and the weight was roughly $24 \mathrm{~kg}$. The particulates were weighed using the Vibra (Shinko Denshi) SJ Series electronic balances built up with the tuning-fork sensor. Its capacity was $220 \times 0.01 \mathrm{~g}$ while its readability was limited to $620 \times 0.01 \mathrm{~g}$. Commercially available epoxy resin LY556 and hardener HY931 were purchased from Tony enterprises, Ojota, Lagos. These were prepared as a control to which no particulate was added and 1, $3,5,31 \%$ (two steps) weight of particulates in the epoxy matrix (Figure 1). A stirrer was improvised to properly mix the epoxy resin and the hardener. This stirrer was a metallic spoon, which aided the proper mixing of the particulates and the matrix. The epoxy resin and the hardener were poured into the bowl and stirred together with the stirrer. The solution was later poured into the plastic mould and then the particulates were added. The mixing of the matrix took about 5 minutes while the pouring into each of the moulds was completed within 2 to 3 minutes. It took about 2 minutes to mix the matrix and the particulates. During the process of mixing, the matrix and pouring of it to each of the moulds up to the mixing of the particulates, heat energy was released into the environment, which was significantly confirmed by the use of an infra-red digital thermometer that revealed a temperature rise from room temperature to about $50^{\circ} \mathrm{C}$ to $60^{\circ} \mathrm{C}$. The epoxy and the hardener were mixed in a bowl of roughly $84 \mathrm{~mm}$ in depth, $138 \mathrm{~mm}$ in diameter and $2 \mathrm{~mm}$ in thickness, and then distributed into a plastic mould of roughly $80 \mathrm{~mm}$ in depth, $65 \mathrm{~mm}$ in diameter and $1 \mathrm{~mm}$ in thickness. The laboratory table on which the materials were prepared was covered with waste paper and rags to prevent having permanent stains on it.

The water experiment was performed in plastic moulds that contained the composite material samples after curing for 76 hours. The weight of each composite was recorded as the initial weight plus the weight of the mould from which the initial weight was obtained. Approximately $190 \mathrm{ml}$ of water was measured with graduated cylinder and transferred into each of the moulds.

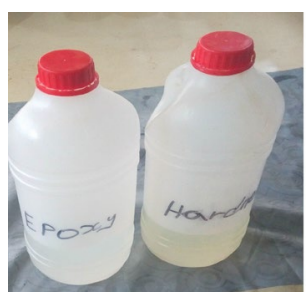

(a)

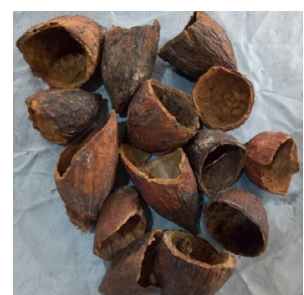

(b)

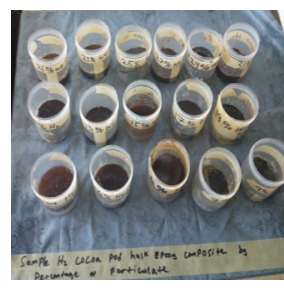

(c)

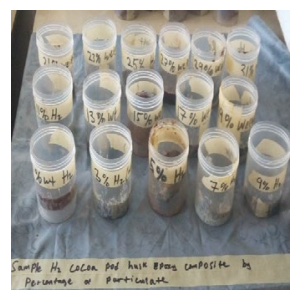

(d)

Figure 1. Cocoa pod husk and matrix used for the experiment

e-ISSN: 2289-7771

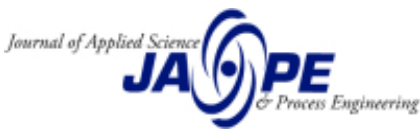


The weights of the composites were taken every seven days. On the days the results were recorded, the water in the moulds was drained, and the weight of the drained composites was taken. The difference between the initial weight of the composite with the mould and the drained weight of the water absorbed by each composite in that space of time was noted. The general scheme for the research is shown in Figure 2 .

\subsection{Water intake dynamics}

The water absorption process in cocoa pod husk composite initiates from the diffusion of water molecules through the surface pores that samples to the epoxy matrix that contains micro gaps where water molecules may be stored, motivating the particulates to smell under the influence of a huge quantity of water. An insight into the motion of water and its intake for the cocoa pod husk epoxy reinforced composite is certainly meant to strengthen the decision on design and fabrication of cocoa pod husk epoxy (CPHE) composite and provide data to use for simulation of the real-life circumstance in the presence of limited data and lost.

To estimate the separating behaviour of the cocoa pod husk composite, diffusion expression, offered in Imoisili et al. [8] was used:

$$
N_{T} / N_{s}=C T^{Z}
$$

where

$N_{T}-$ absorbed water quantity at time $\mathrm{T}$,

$C$ - interactive symbol

$N_{S}-$ absorbed water quantity at saturation

$Z$ - response indicator between the patterns

Notice that

$$
Z=\left\{\begin{array}{l}
0.5 \\
>1 \\
0.5<Z<1
\end{array}\right.
$$

e-ISSN: 2289-7771

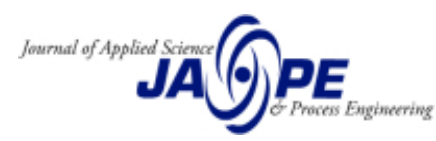




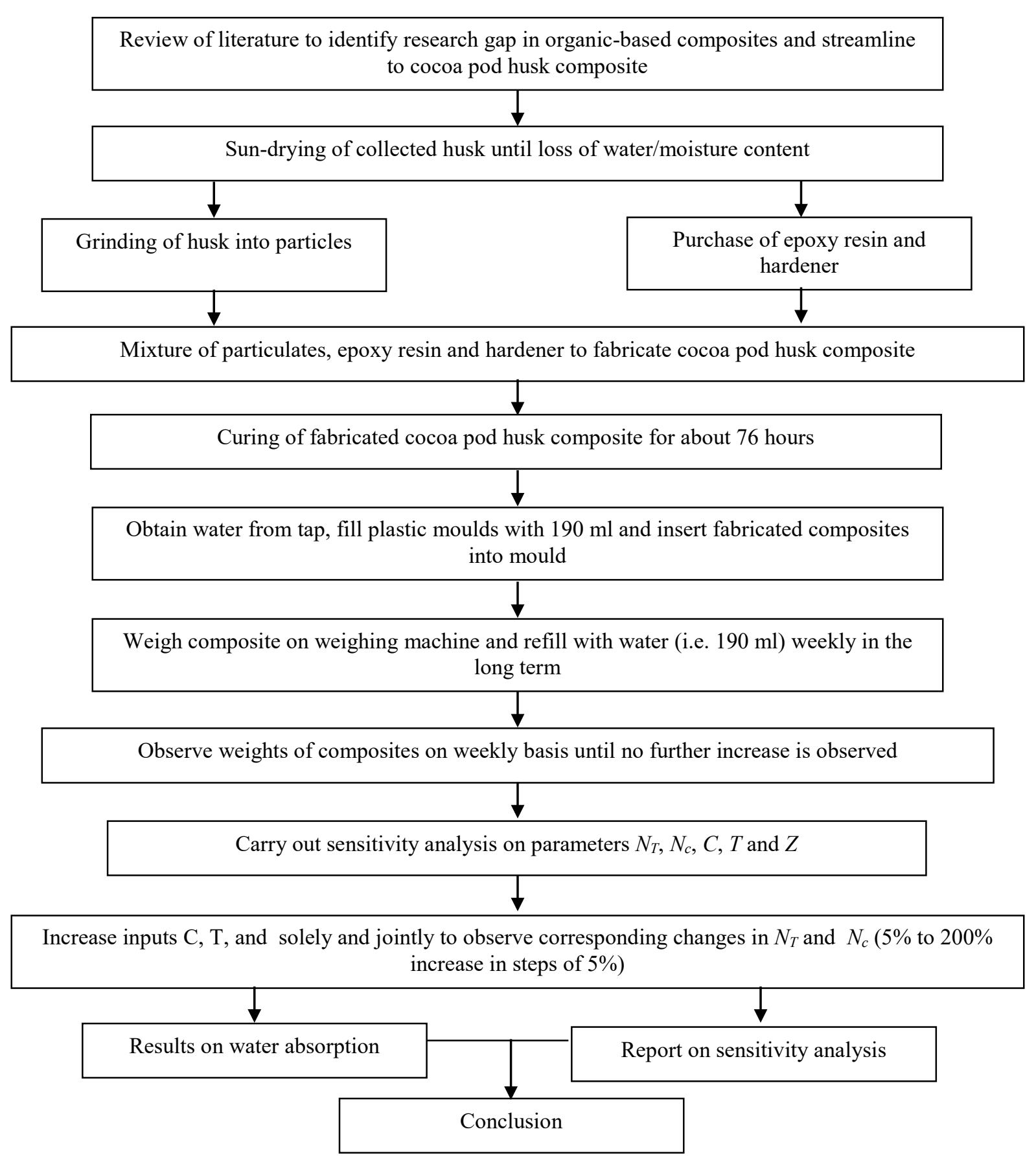

Figure 2. Research scheme for the cocoa pod husk for water absorption process 
In examining the separating behaviour of cocoa pod husk composite, we concur with the established equation by Imoisili et al. [8] that relates the ratio of the absorbed water at time, $T$, referred to as $N_{T}$, as well as the ratio of the absorbed water at saturation, $N s$, with the product of the interactive symbol, $C$, and the power of the time, $T$. The limits of $Z$ that unfolds may be categorized as three (Table 1). In the first instance, $Z$ may assume a value of 0.5 . Secondly, $Z$ may be higher than 1 , and lastly, $Z$ could be assigned a value such that 0.5 is less than it and it is also less than 1 in its assigned value.

The description of the $N_{T} / N_{S}$ quotient may be characterized by the elevated response of trend 2 diffusion (anomalous), as elaborated by Imoisili et al. [8] which was established by the authors as the Fickian diffusion phenomenon. The form of Fickian's law is followed in which water increases with the square root of on a straight line and slightly reduces to maintain saturation platform [8]. Diffusion constant $K$ is obtained from the expression [8]:

$\frac{N_{T}}{N_{s}}=\frac{4}{a}\left(\frac{K}{\pi}\right)^{\frac{1}{2}} T^{\frac{1}{2}}$

where $a$ is the thickness of the fabricated composite materials

\section{Results and discussion}

According to the objective of the composite manufactured in this study, $C 13$ was compared with all others reported by Imoisili et al. [8]. Four categories were claimed to have been manufactured by Imoisili et al. [8], namely, $C 15, C 110, C 120$ and $C 130$, which were $5 \%, 10 \%, 20 \%$ and $30 \%$ by the composition of reinforcements in epoxy resin composite. The analysis produced comparative results on the response pattern behaviour (Figure 3), interactive factor per composite category (Figure 4), diffusion factor analysis as per composite category (Figure 5), initial absorbed water as per group (Figure 6) and average absorbed water (Figure 7).

Figure 3 shows the factor $Z$. In the equation that we obtained from Imoisili et al. [8], $Z$ is a factor in the equation, and others are $N_{T}, N_{S}$, and $T$. For the computation, we declared that for any composite considered the value of $Z$, it should be less than 0.5 to follow Fickian's pattern of water absorption. However, when it is greater than 0.5 , it is said to be an anomalous diffusion. Figure 3 represents the response pattern factor for all the composites, which indicates the behaviour of each of the composites in Fickian's expression. By testing the composites $C I 5, C I 10, C I 20, C I 30$ and $C 13$ in water, we could confirm or refute whether the behaviour of the composite concur with Fickian's assumptions first increases to a saturation point and it goes with the square root of time. CI5, which was more than 0.5 indicated an anomalous behaviour while $C I 10$ that was close to 0.5 was within the range of Fickian's behaviour. $C 13$ had the least response pattern factor, indicating that it was constantly within Fickian's behaviour. It was the least likely to exceed the range. This confirmed the choice of $C 13$ from our previous experiment to be a good choice in resistance characteristics. 


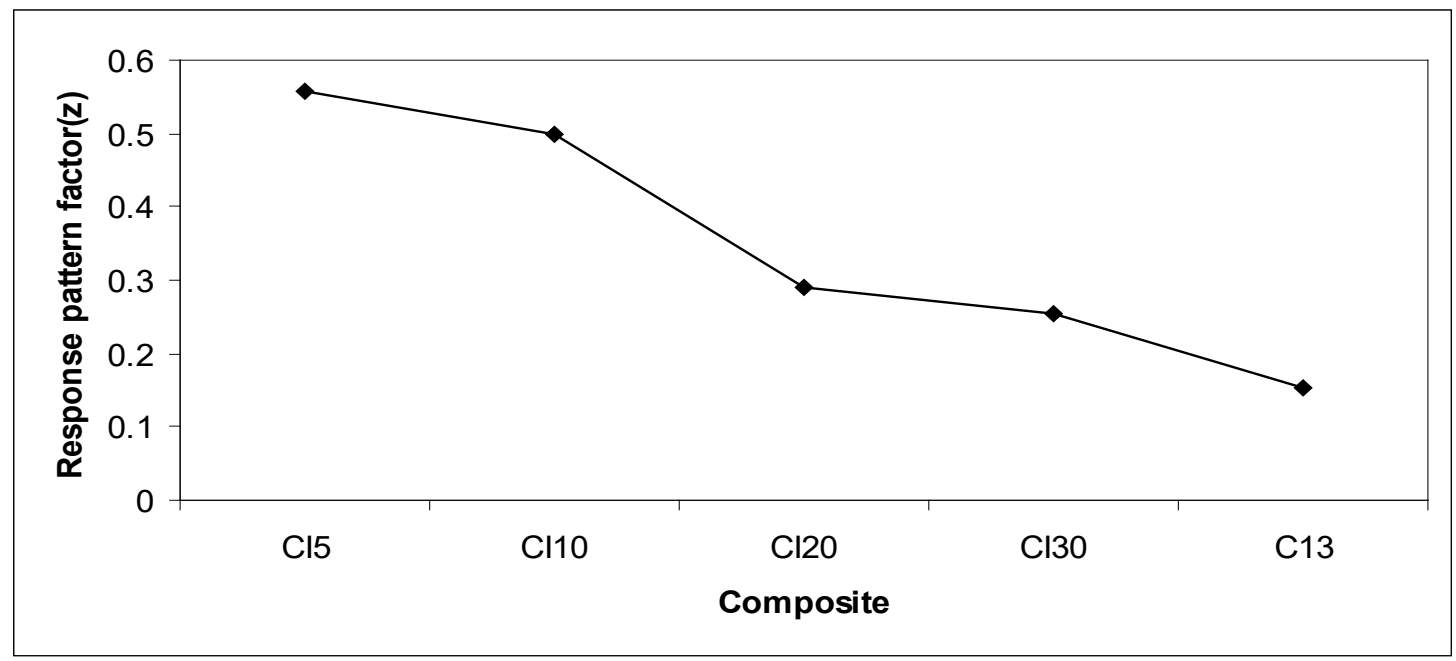

Figure 3. Response pattern factor of composites

Figure 4 considers the interactive factor, $C$. From the literature, it was not emphasized but it is a linear factor applied directly. Considering the interactive factor, $C$, from the literature, it was not emphasized but it is a linear factor applied directly. Considering the interactive factor $C$, for all the composites, $C 13$ maintained an approximately average value similar to $C I 20$ and $C 130$. The good relationship between all the factors was considered in the water absorption process. $C I 5$, having the highest value of interactive factor might not have good interaction with the other factors and most likely to be the reason that it was behaving outside the Fickian's behaviour. $C I 10$ behaved almost in a similar manner to CI5. However, CI20 and CI30 were of average interactive behaviour alongside C13.

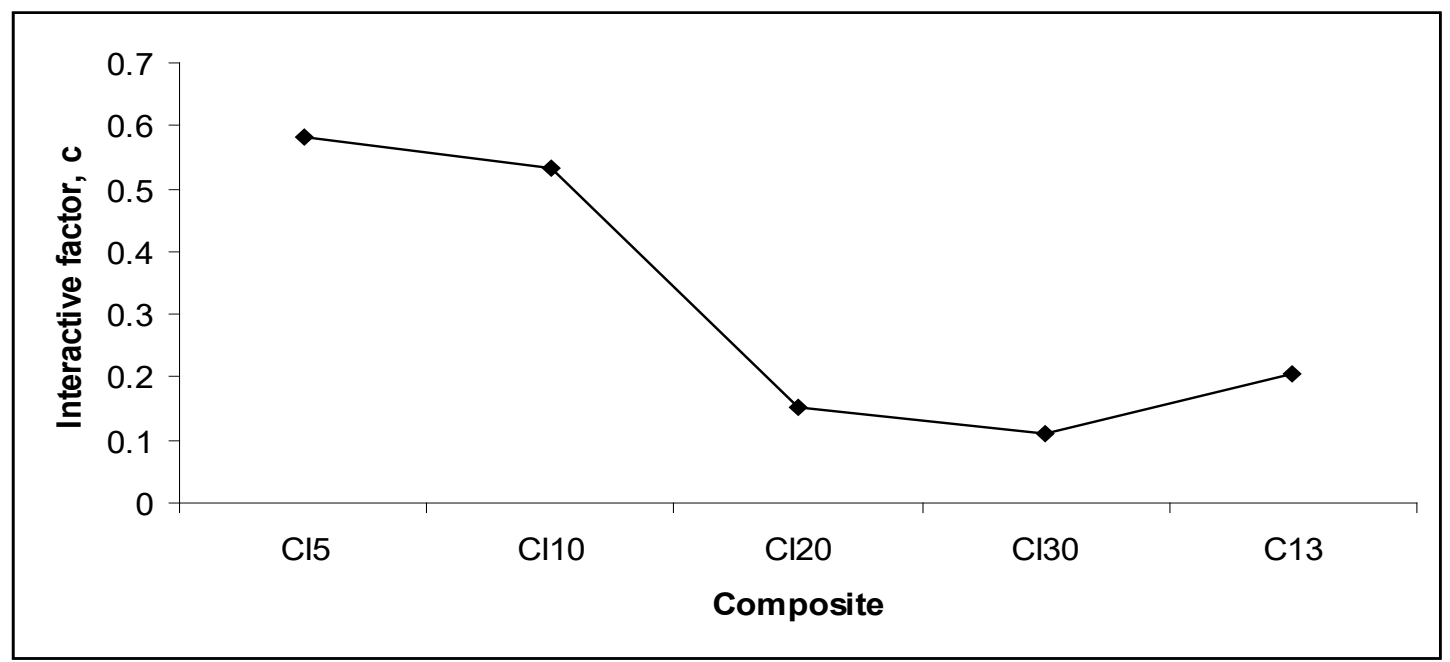

Figure 4. The interactive factor of composites

e-ISSN: 2289-7771

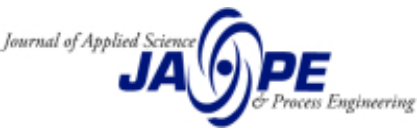


Figure 5 shows the diffusion factor, $K$, which is a factor in the second equation. The values obtained were of infinitesimal range that indicated the level of water absorption for all the composites.

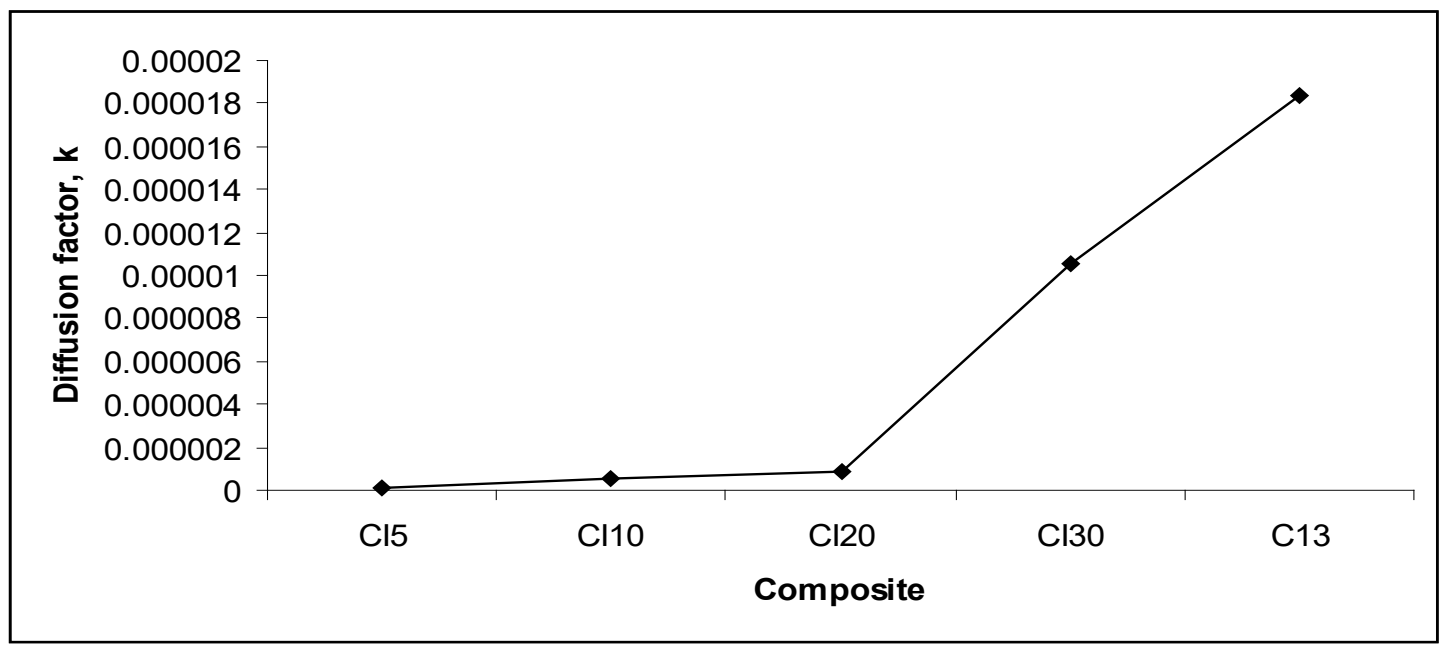

Figure 5. Diffusion factor of composites

Figure 6 shows the results of the initial water absorption of composites. This was the first observed water absorption when the experiment started with the value obtained at time $\mathrm{T}$ before varying the factors to observe the various effects.

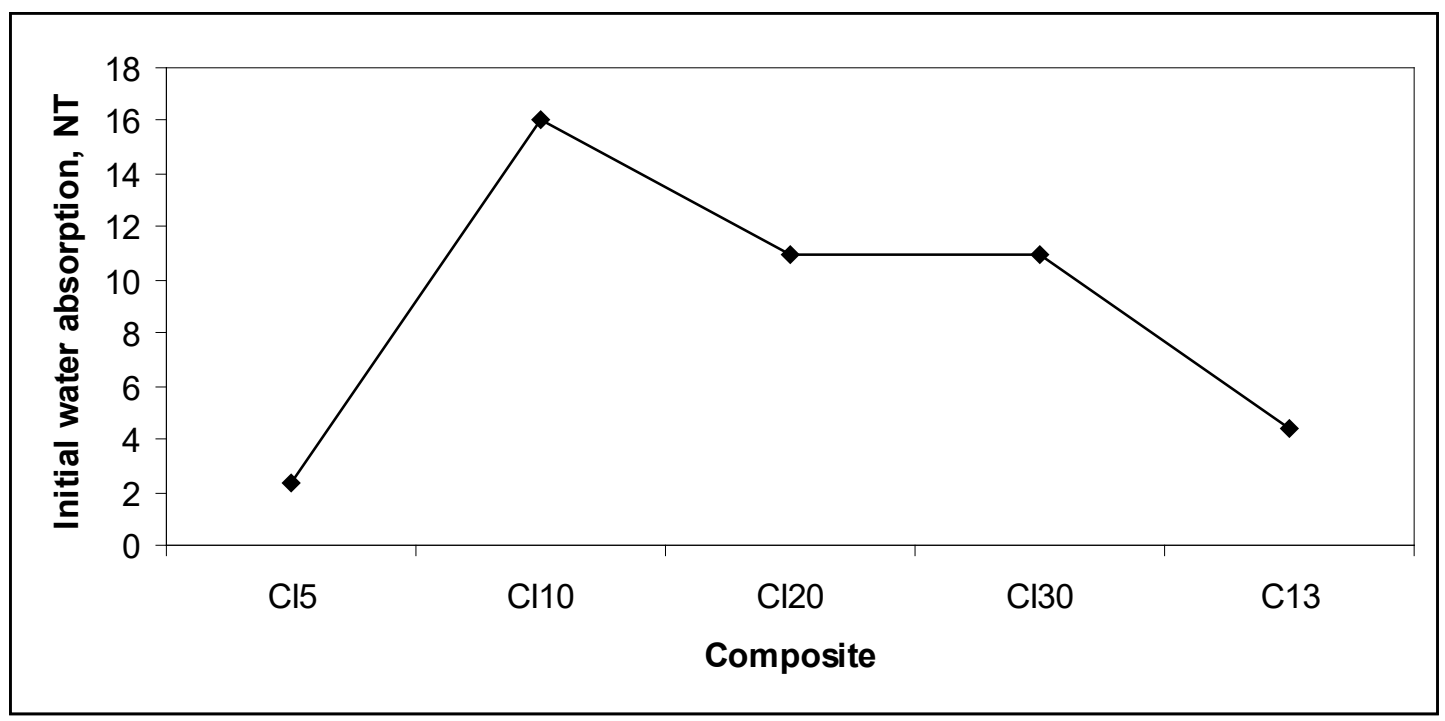

Figure 6. Initial absorbed water of composites

These initial values that are different from our calculations may somehow affect the accuracy of our analysis. But to avoid this problem, we used the average performance values in our analysis. Figure 7 is the 
average absorbed divided by the number of times that the experiments were conducted (i.e. when readings were done). C130 indicated that the more the presence of cellulose material as reinforcement in the composite, the more water absorption quantity was experienced. However, on average, the remaining four materials had moderate water absorption behaviour.

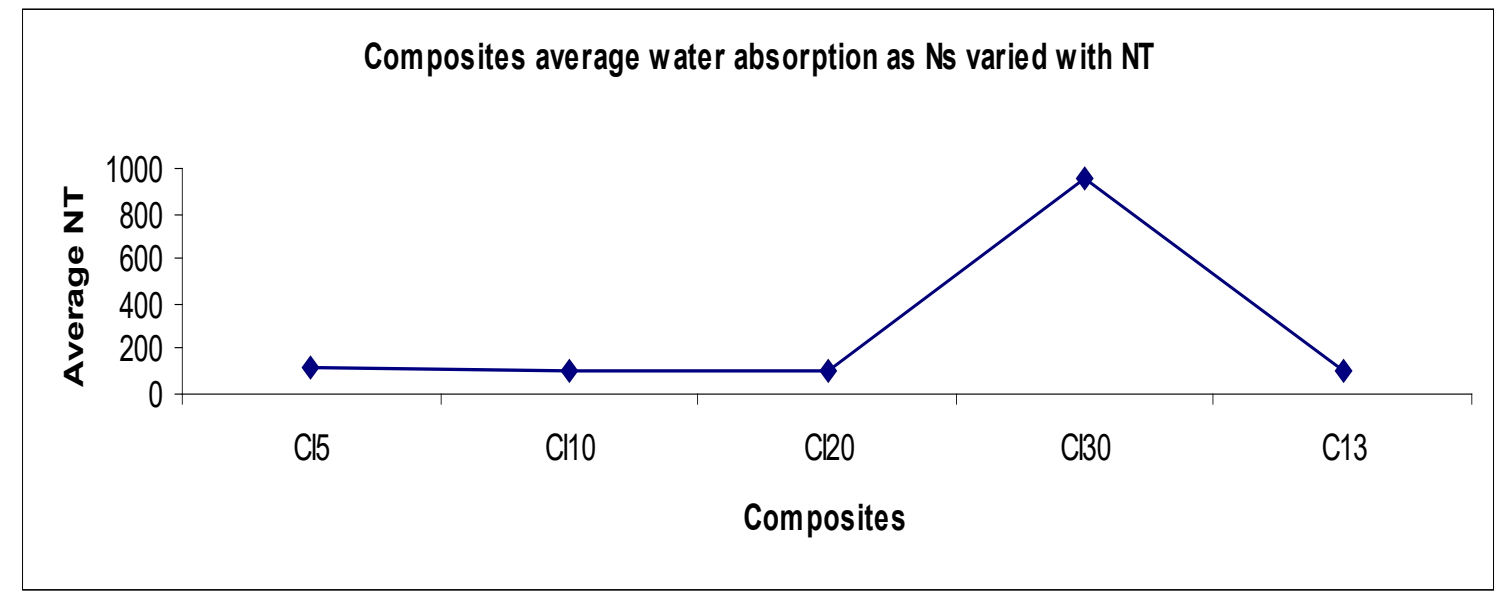

Figure 7. Average absorbed water, $N_{T}$, with $N_{S}$ varying

The following Table 1 is the summary of the data obtained from the experiment.

Table 1. Water absorption characteristic parameters

\begin{tabular}{|c|c|c|c|c|c|c|c|c|c|c|c|c|c|}
\hline (1) & (2) $\mathrm{N}_{1}$ & (3) $\mathrm{N}_{2}$ & (4)a $\mathrm{mm}$ & Water abs & rption a & er days & $\%$ & & & & & & \\
\hline & & & & 7 & 14 & 21 & 31 & 35 & 42 & 49 & 56 & 63 & 70 \\
\hline 1 & 86.95 & 5.2 & 20 & 4.95 & 4.6 & 7.5 & 5.9 & 5.2 & 9.8 & 14.2 & 8.0 & 6.1 & 2.9 \\
\hline 3 & 101.73 & 9.2 & 25 & 5.58 & 7.7 & 7.8 & 8.2 & 9.2 & 8.4 & 11.1 & 10.5 & 7.6 & 9.0 \\
\hline 5 & 99.26 & 6.0 & 20 & 5.24 & 5.4 & 6.3 & 6.1 & 6.0 & 7.4 & 8.5 & 7.1 & 7.3 & 7.9 \\
\hline 7 & 66.65 & 14.9 & 15 & 7.43 & 12.8 & 12.8 & 17.7 & 14.9 & 16.1 & 17.4 & 17.3 & 15.4 & 15.8 \\
\hline 9 & 96.39 & 11.4 & 20 & 5.47 & 8.9 & 9.3 & 11.7 & 11.4 & 12.7 & 13.2 & 11.8 & 11.8 & 11.0 \\
\hline 11 & 98.65 & 7.1 & 23 & 4.71 & 6.8 & 6.3 & 7.8 & 7.1 & 12.5 & 13.7 & 11.3 & 6.8 & 9.2 \\
\hline 13 & 88.69 & 5.0 & 17 & 4.41 & 6.0 & 5.0 & 5.3 & 5.0 & 6.4 & 7.1 & 5.8 & 5.6 & 6.1 \\
\hline 15 & 76.49 & 22.4 & 17 & 8.69 & 12.5 & 11.3 & 14.7 & 22.4 & 16.3 & 16.2 & 16.1 & 15.2 & 16.3 \\
\hline 17 & 93.80 & 8.2 & 25 & 6.06 & 7.2 & 6.4 & 8.2 & 8.2 & 8.9 & 9.3 & 9.4 & 8.1 & 8.8 \\
\hline 19 & 83.36 & 13.4 & 18 & 17.72 & 7.7 & 6.7 & 10.2 & 13.4 & 17.0 & 18.3 & 15.2 & 13.0 & 14.1 \\
\hline 21 & 79.37 & 18.3 & 18 & 10.56 & 12.7 & 14.5 & 18.0 & 18.3 & 21.1 & 23.6 & 25.6 & 26.3 & 29.5 \\
\hline 23 & 87.25 & 15.0 & 23 & 9.44 & 10.8 & 12.6 & 14.8 & 15.0 & 17.3 & 18.3 & 18.1 & 18.9 & 21.4 \\
\hline 25 & 97.08 & 6.2 & 23 & 3.97 & 7.0 & 5.2 & 5.4 & 6.2 & 7.1 & 6.7 & 7.8 & 5.1 & 7.2 \\
\hline 27 & 79.23 & 17.8 & 20 & 9.72 & 13.7 & 14.3 & 16.6 & 17.8 & 20.0 & 21.1 & 22.5 & 22.3 & 24.9 \\
\hline 29 & 85.73 & 3.6 & 15 & 1.75 & 7.1 & 3.1 & 4.4 & 3.6 & 5.6 & 7.6 & 7.0 & 6.2 & 8.3 \\
\hline 31 & 78.80 & 19.4 & 20 & 12.54 & 15.1 & 16.2 & 18.2 & 19.4 & 21.1 & 23.4 & 23.9 & 24.5 & 27.3 \\
\hline Control & 53.53 & 1.8 & 10 & 0.11 & 1.8 & 1.5 & 2.2 & 1.8 & 0.8 & -0.3 & 54.3 & 0.7 & 2.0 \\
\hline
\end{tabular}

Key: (1) Particulate loading; (2) Initial weight; (3) Saturation weight; (4) - Thickness

e-ISSN: 2289-7771 
Figure 8 follows the pattern described in Figure 6, while Figures 9 and 10 follow the pattern detailed in Figure 7.

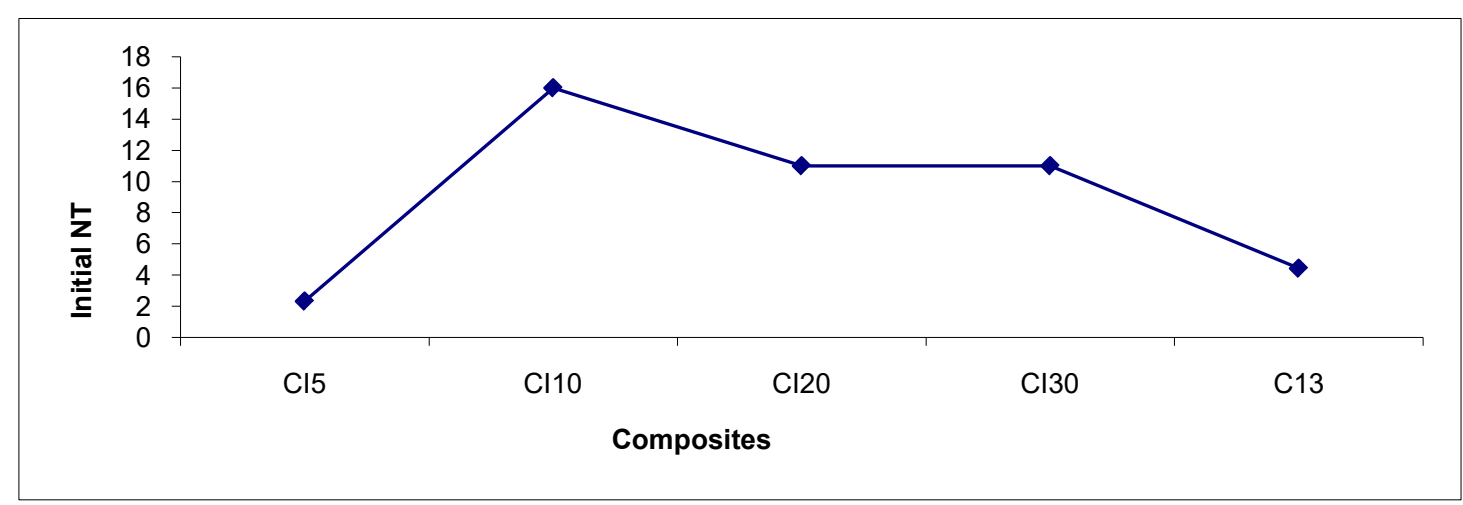

Figure 8. Composites initial water absorption

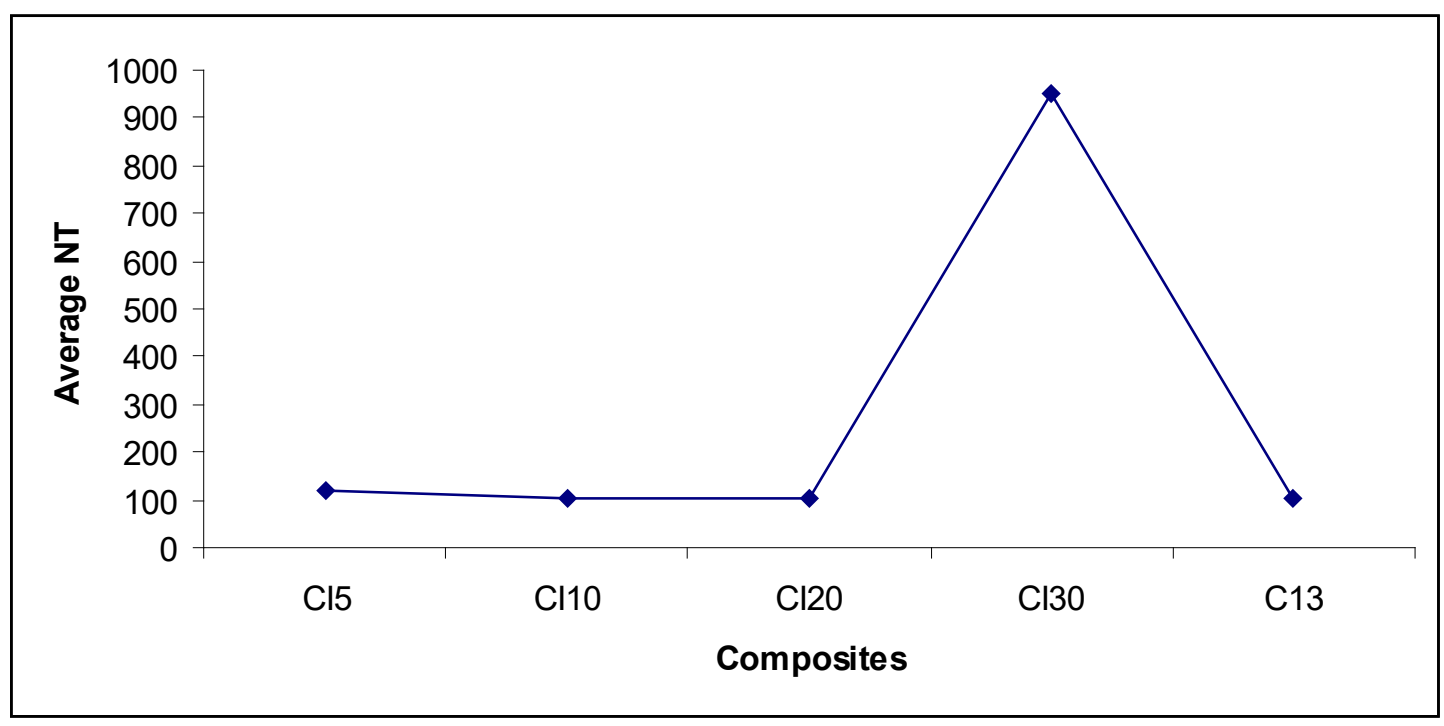

Figure 9. Average water absorption as Ns varied with $\mathrm{N}_{\mathrm{T}}$

e-ISSN: $2289-7771$

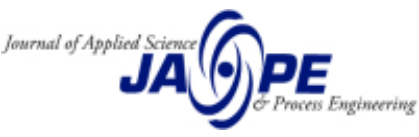




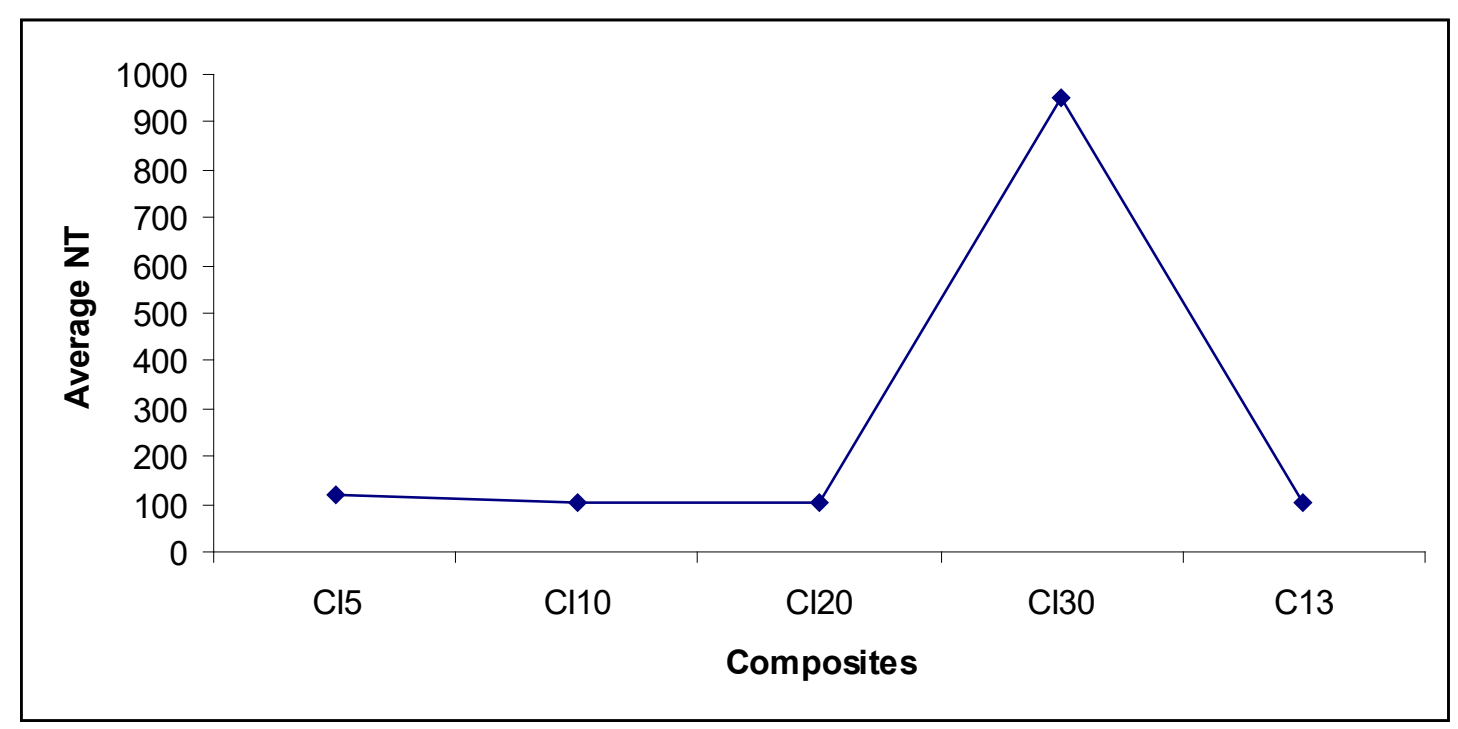

Figure 10. Average NT of composites as only $\mathrm{C}$ varied with $\mathrm{N}_{\mathrm{T}}$

Saturation weight: From 5.2g for the 1\% particulate loading of cocoa-reinforced composite, the saturation weight rose to $9.2 \mathrm{~g}$ in $3 \%$ particulate loading. However, it fluctuated again by dropping to $6 \mathrm{~g}$ with 5\% particulate loading and this fluctuation continued until it reacted an all-time height of $22.4 \mathrm{~g}$ with $15 \%$ particulate loading. Thereafter the fluctuation continued and finally it reached $19.4 \mathrm{~g}$ with $31 \%$ particulate loading. Nonetheless, the least value, belonging to $29 \%$ particulate loading was still about $200 \%$ of the control sample, indicating that it could take more water than the control sample before failure.

Thickness: This category recorded an increase of $25 \%$ in thickness from its original thickness in $1 \%$ particulate loading in terms of thickness revealed an increase and decrease consecutively with a maximum height of $25 \mathrm{~g}$ obtained for $17 \%$ particulate loading. The variations continued until a final value of $20 \mathrm{~g}$ at $31 \%$ particulate loading was attained, which was twice the value of the control specimen where only epoxy resin was used.

Initially, all the weight fraction particulate reinforced cocoa pod husk composites were tested for water absorption properties. After repeated experiments, it was noted that $13 \mathrm{wt} \%$ cocoa pod husk reinforced composite was better than other weights of composites. It followed the Fickian's theory and was the least that absorbed water, which followed the control sample in performance. Furthermore, it was more economical to choose it since it required more reinforcements, which were free of cost than its competing samples with similar water-resistance performance; more ratio of reinforcement to epoxy was required for the $13 \mathrm{w} \%$ reinforced composite than other water-resistant samples. There was an economy to conserve the use of epoxy, and this further reduces the production cost of composite manufacturing. Consequently, for further experimentation and analysis, the $13 \mathrm{w} \%$ reinforced cocoa pod husk composite was developed. At a further stage in this work, the results were compared with that of Imoisili et al. [8].

From the results obtained it was observed that the water absorption increased with the number of days as the mass of drained composites remarkably rose to give a notable increase in the percentage water absorption by each of the composites. Notwithstanding, the increase in water absorption was first rapid but dropped with time as the absorption approached the saturation level where there was no further increase in weight (Table 2). This made the absorption to relation follow the Fickian relation, and the equation was further considered in its natural logarithm [8]:

e-ISSN: 2289-7771

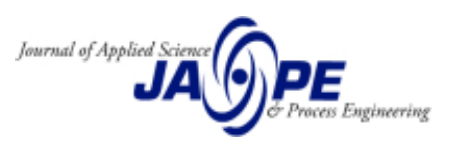




$$
\begin{aligned}
& \log _{10}\left(N_{T} / N_{\mathrm{s}}\right)=\log _{10} \mathrm{C}+\mathrm{Z} \log _{10} \mathrm{~T} \\
& \log _{10} N_{T}-\log _{10} N_{\mathrm{s}}=\log _{10} \mathrm{C}+\mathrm{Z} \log _{10} T
\end{aligned}
$$

Table 2. Experimental time

\begin{tabular}{llrrrlll}
\hline S/No & Time (days) & $\begin{array}{l}\text { Time } \\
\text { (minutes) }\end{array}$ & $\begin{array}{l}\text { Square root of } \\
\text { time }\left(\min ^{1 / 2}\right)\end{array}$ & S/No & Time (days) & $\begin{array}{l}\text { Time } \\
(\text { minutes })\end{array}$ & $\begin{array}{l}\text { Square root of } \\
\text { time }\left(\mathrm{min}^{1 / 2}\right)\end{array}$ \\
\hline 1 & 7 & 10080 & 100.40 & 6 & 42 & 60480 & 245.93 \\
2 & 14 & 20160 & 141.99 & 7 & 49 & 70560 & 265.63 \\
3 & 21 & 30240 & 173.90 & 8 & 56 & 80640 & 283.97 \\
4 & 31 & 44640 & 211.28 & 9 & 63 & 90720 & 301.20 \\
5 & 35 & 50400 & 224.50 & 10 & 70 & 100800 & 317.49 \\
\hline
\end{tabular}

Table 3. Particulate loading and the Fickian diffusion parameters

\begin{tabular}{llllllll}
\hline $\begin{array}{l}\text { Particulate } \\
\text { loading }\end{array}$ & $Z$ & $C$ & $a$ mm & $N_{T} / N_{S}$ & $T$ & $16 T$ & $K$ \\
\hline 1 & -0.62281 & 880.0131 & 20 & 1.425439 & 30240 & 483840 & 0.00168 \\
3 & 0.123118 & 0.237671 & 25 & 0.846482 & 30240 & 483840 & 0.000926 \\
5 & -0.07479 & 2.268148 & 20 & 1.048495 & 30240 & 483840 & 0.000909 \\
7 & 0.826381 & 0.00017 & 15 & 0.859438 & 30240 & 483840 & 0.000343 \\
9 & 0.583222 & 0.001995 & 20 & 0.818596 & 30240 & 483840 & 0.000554 \\
11 & 0.557948 & 0.002784 & 23 & 0.880342 & 30240 & 483840 & 0.000847 \\
13 & 0.152242 & 0.205581 & 17 & 0.988814 & 30240 & 483840 & 0.000584 \\
15 & 0.674795 & 0.000478 & 17 & 0.504962 & 30240 & 483840 & 0.000152 \\
17 & 0.647183 & 0.000983 & 25 & 0.780234 & 30240 & 483840 & 0.000786 \\
19 & 1.062316 & $8.78 \mathrm{E}-06$ & 18 & 0.504942 & 30240 & 483840 & 0.000171 \\
21 & 0.541609 & 0.002977 & 18 & 0.795314 & 30240 & 483840 & 0.000424 \\
23 & 0.413778 & 0.011741 & 23 & 0.838808 & 30240 & 483840 & 0.000769 \\
25 & 0.06994 & 0.407944 & 23 & 0.839404 & 30240 & 483840 & 0.00077 \\
27 & 0.388982 & 0.014511 & 20 & 0.802697 & 30240 & 483840 & 0.000533 \\
29 & 0.85571 & 0.000128 & 15 & 0.875817 & 30240 & 483840 & 0.000357 \\
31 & 0.293926 & 0.040366 & 20 & 0.837484 & 30240 & 483840 & 0.00058 \\
Control & 1.008374 & $2.42 \mathrm{E}-05$ & 10 & 0.79798 & 30240 & 483840 & 0.000132 \\
\hline
\end{tabular}

The results for $35^{\text {th }}$ day were taken for the values of $\mathrm{N}_{\mathrm{s}}$ because most of the composites behaved close to saturation. For example, composites with $13 \%$ maintained a constant value of $8.2 \mathrm{~g}, 21 \%$ had a very close value of $18.3,23 \%$ with $14.8 \mathrm{~g}$ and $15 \mathrm{~g}, 13 \%$ with $5.3 \mathrm{~g}$ and $5 \mathrm{~g}, 5 \%$ with $6.1 \mathrm{~g}$ and $6 \mathrm{~g}$. Hence the values of absorbed water after 35 days were applied as the Ns for further analysis. Considering equation (3), two days: day 21 and day 31 were used to generate simultaneous equations with two unknown variables for each composite and the results of $z$ and $c$ obtained were applied to equation (4) for the values of $K$. The following simultaneous equations exist (see Appendix, Table A). From Equation (2), making $K$ the subject of formula and the parameters of the equation used in Table 3 and for subsequent computations:

\subsection{Sensitivity analysis}

To determine the sensitivity analysis of the water absorption model characterized by the dependent variable, $N_{T}$, and the independent variables (or factors) $C, Z, T$, and $N_{s}$, the variations of one factor, two factors, three factors and all the four factors were considered over changes from $5 \%$ to $200 \%$, described as

e-ISSN: $2289-7771$

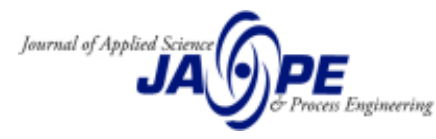


scenarios with cases. The information is useful in composite fabrication in a drive to determine what variable to adjust to obtain the most advantageous performance of composites (Table 4a-d).

\subsection{Comparative analysis of the current paper and Imoisili et al.'s paper [8]}

The data on all the reinforced water samples $(5 \%, 10 \%, 20 \%$ and $30 \%$ cocoa reinforced epoxy composites) showcased by Imosili et al. [8] was subjected to sensitivity analysis as a validation process to ensure the workability of the procedure adopted in this study as well as to ensure measurement precision. The starting point was to refer to Table 1 of Imoisili et al.'s [8] work and the following values were obtained for each percentage composite samples, Table 5. From the extracted data, $\mathrm{N}_{\mathrm{T}}$ and the initial weight of the composites were not directly recorded in Imoisili et al. [8] but the percentage of water absorption as obtained from Figure 1 of the work was used as the $\mathrm{N}_{\mathrm{T}}$ values (Table 6). As an example, for 5\% cocoa reinforced composite, which took the time, $T$, of 50 minutes, $\mathrm{N}_{\mathrm{s}}$ was calculated with the rearranged equation (1) of this work, originally generated by Imoisili et al. [8]. This gave the value of $N_{s}$ to be 2.3181. Other values were computed in the same manner and used to generate the sensitivity analysis to compare the sensitivity behaviour of the variables in this work with them. The sensitivity analysis embarked upon yielded a range of test values from $5 \%$ to $200 \%$ increments, which was consistent with the earlier analysis carried out on the data obtained from experiments in this work. After careful extraction of values, the following summary of data points to guide the sensitivity analysis was obtained. 
Table 4a. Sensitivity ranking of $\mathrm{N}_{\mathrm{T}}$ when only one factor was varied for $13 \%$ coca pod husk composite

\begin{tabular}{llllllllll}
\hline Case & Description & Sum & \multicolumn{3}{c}{ Average } & \multicolumn{3}{c}{ Ratio } & \multicolumn{2}{c}{ Rank } & Remark \\
\hline & & $Z$ & $N_{T}$ & $Z$ & $N_{T}$ & $Z$ & $N_{T}$ & & \\
1 & $N_{s}, c$ and $T$ are constants while $Z$ varies with $N_{T}$ & 12.33 & 25306.40 & 0.31 & 632.66 & - & 312.42 & 1 & Most sensitive \\
\hline
\end{tabular}

Table $4 \mathrm{~b}$. Sensitivity ranking of $\mathrm{N}_{\mathrm{T}}$ when two factors were varied for $13 \%$ cocoa pod husk composite

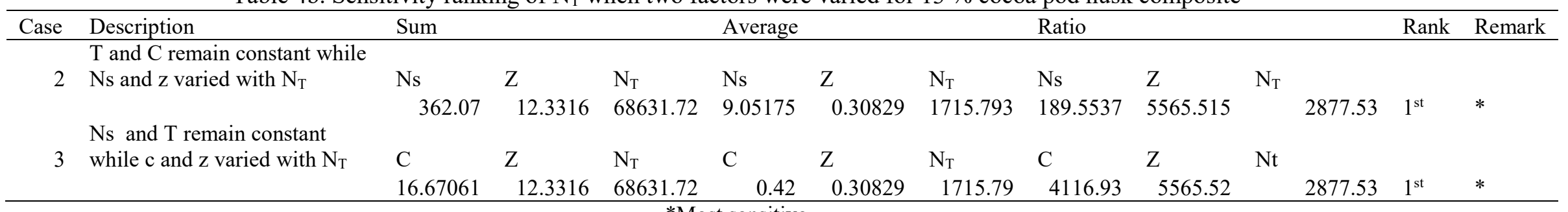
*Most sensitive

Table $4 \mathrm{c}$. Sensitivity ranking of $\mathrm{N}_{\mathrm{T}}$ when three factors were varied for $13 \%$ cocoa pod husk composite

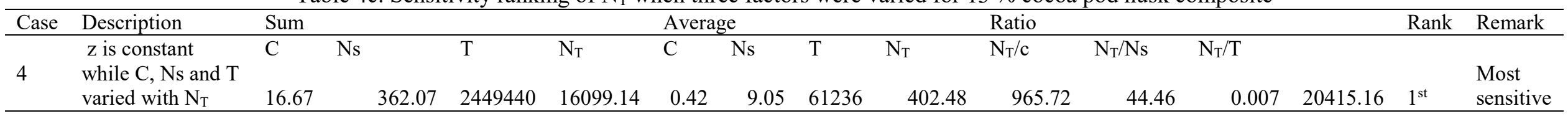

Table 4d. Sensitivity ranking of $\mathrm{N}_{\mathrm{T}}$ when four factors were varied for $13 \%$ cocoa pod husk composite

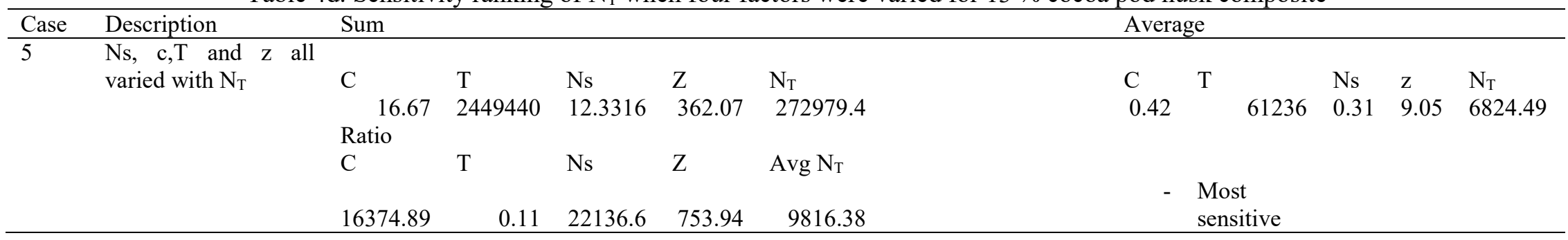

e-ISSN: 2289-7771 
Table 5. Data values on 5\% to $30 \%$ cocoa reinforced composite with values of z, c, and $\mathrm{K}$ from Imoisili et al. [8]

\begin{tabular}{llll}
\hline \% reinforcement & $\mathrm{Z}$ & $\mathrm{C}$ & $\mathrm{K}\left(\mathrm{m}^{2} / \mathrm{s}\right)$ \\
\hline $5 \%$ & 0.5587 & 0.5802 & $1.437 \times 10^{-7}$ \\
$10 \%$ & 0.4995 & 0.5334 & $5.446 \times 10^{-7}$ \\
$20 \%$ & 0.2901 & 0.1532 & $9.122 \times 10^{-7}$ \\
$30 \%$ & 0.2540 & 0.1120 & $105.899 \times 10^{-7}$ \\
\hline
\end{tabular}

Table 6. Extracted values from Imoisili et al. [8] for validation of sensitivity analysis

\begin{tabular}{lllllll}
\hline $\begin{array}{l}\text { Reinforcement } \\
\text { \% cocoa } \\
\text { composite }\end{array}$ & Acronym & $\mathrm{Z}$ & $\mathrm{C}$ & $\mathrm{N}_{\mathrm{s}}$ & $\mathrm{T}$ & $\mathrm{N}_{\mathrm{T}}$ \\
\hline $5 \%$ & CI5 & 0.5587 & 0.5334 & 2.3181 & 50 & 11 \\
$10 \%$ & CI10 & 0.4995 & 0.5334 & 4.2504 & 50 & 16 \\
$20 \%$ & CI20 & 0.2901 & 0.1532 & 48.2612 & 50 & 11 \\
$30 \%$ & CI30 & 0.254 & 0.5802 & 105.82 & 50 & 11 \\
\hline
\end{tabular}

Note: Acronym for 13wt particulate cocoa pod husk epoxy composite (current work): C13

The generated values of $N_{T}$ from Imoisili et al.'s [8] work are shown in Tables 7 to 10. In this work, the focus was the estimation of $\mathrm{N}_{\mathrm{T}}$, which indicated the amount of water absorbed in a period, $\mathrm{T}$. Thus, the interest was to observe the composite with the maximum $\mathrm{N}_{\mathrm{T}}$, which was obtained from the sensitivity table. The pursuit of sensitivity in our analysis was motivated by the need to establish the variables that influenced water absorption forecasts, thus aiding the adequate understanding of the water absorption process entirely. In the water absorption of cocoa reinforced composite, there was a complete absence of sensitivity information and this attempt in the amount research aids to establish the crucial variables that may require extra information for more effective monitoring of the water absorption process. The sensitivity analysis information will then help in arriving at actions that would assist to build up the effective aspects of the water absorption test process initiated for effective composite design.

e-ISSN: 2289-7771

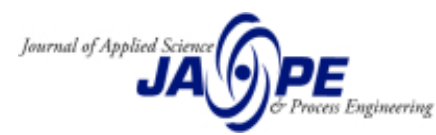




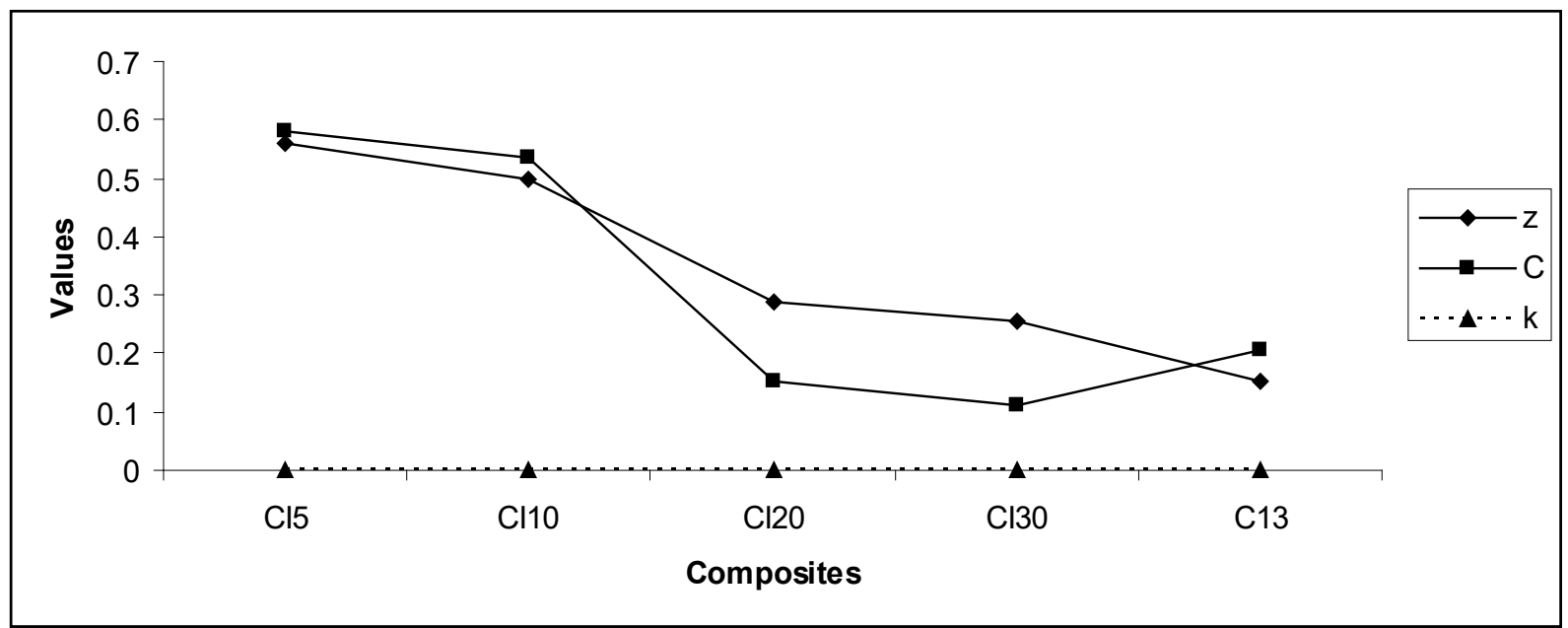

Figure 11. Response constant (z), interactive constant (C) and diffusion constant (k) versus composites

From Figure 11, the constant indicating response between patterns, $Z$, was the maximum for $C I 5$ and the minimum for $C 13$. This was based on the calculations from experiments. Similar to the previous observation, the maximum value of an interactive constant, $C$, was found in $C 15$ and the minimum in CI30. The diffusion constant, $k$, indicated the maximum value for $C 13$ and the minimum for CI5.

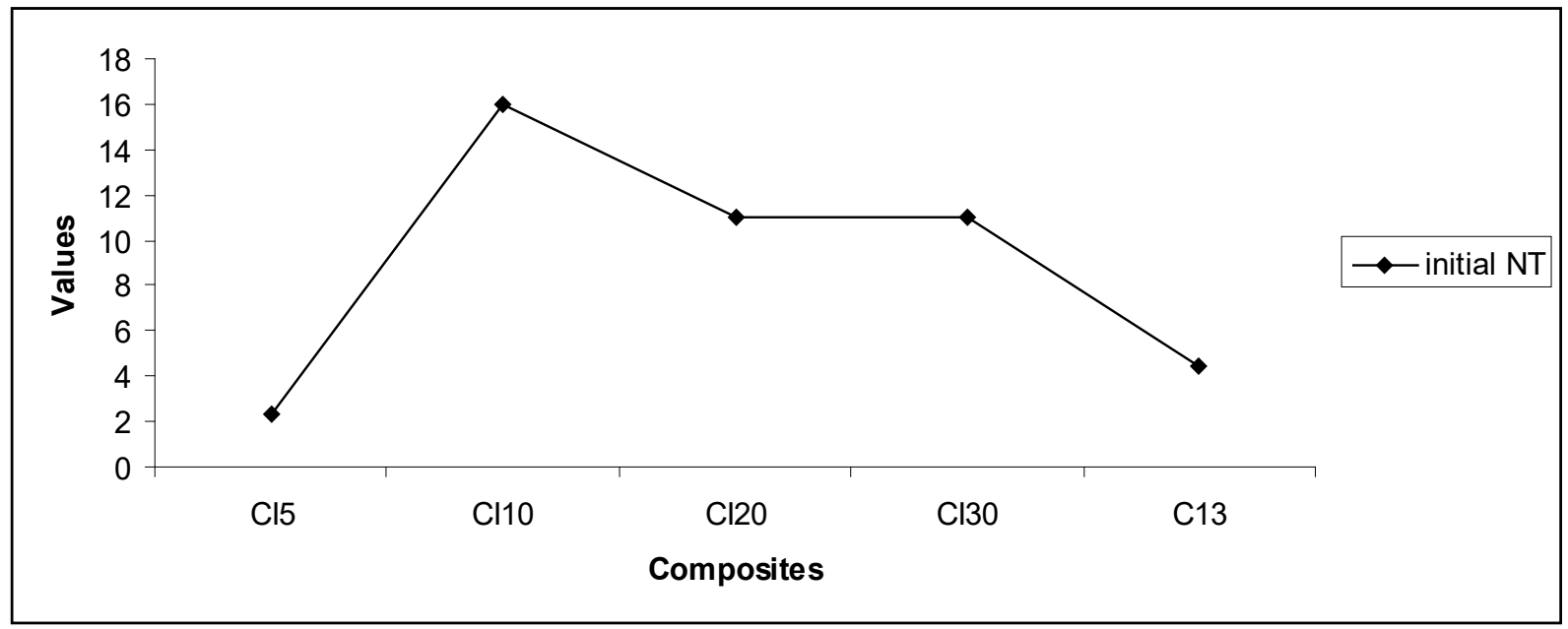

Figure 12. Initial $N_{T}$ versus composites

The initial values of absorbed water were the maximum in $C I 10$ and the minimum in $C I 5$, asindicated in Figure 12 while $C 13$ was next to the minimum value.

e-ISSN: 2289-7771

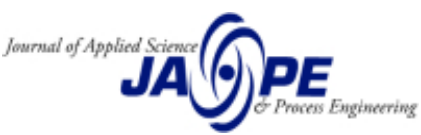




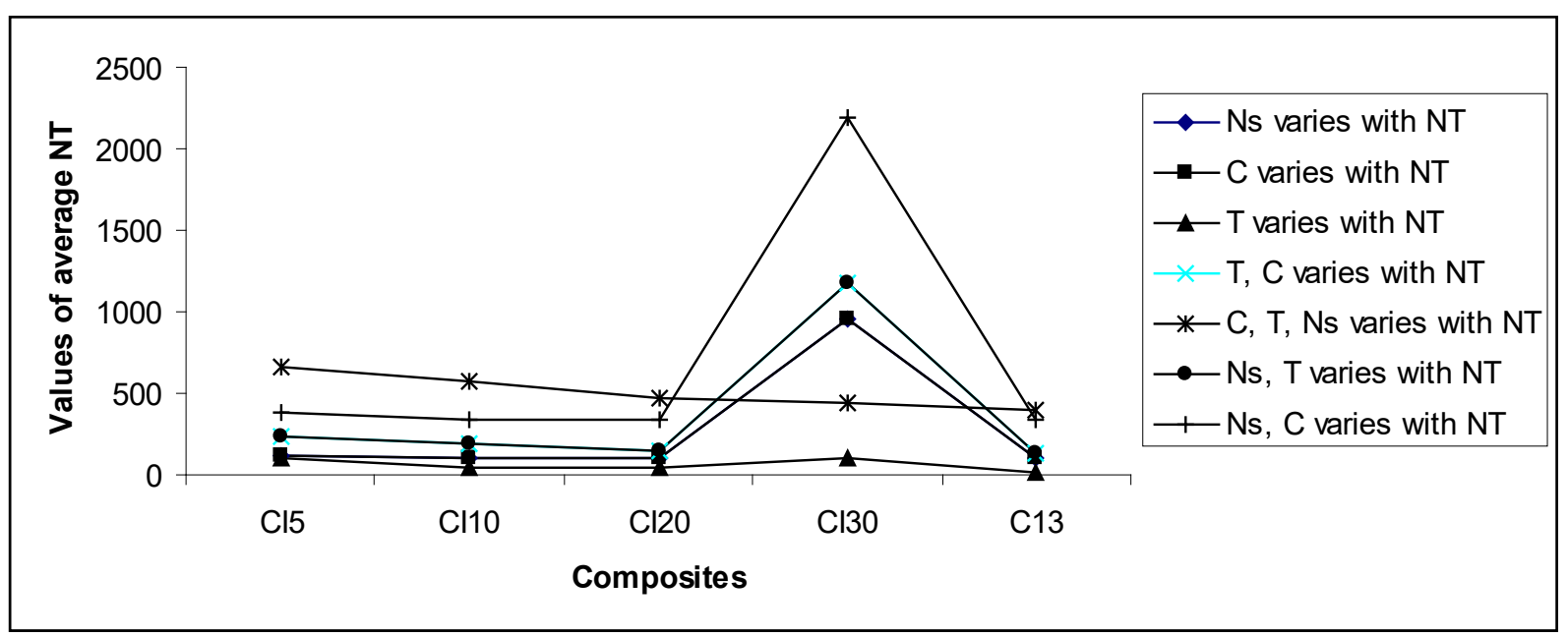

Figure 13. Values of average $N_{T}$ versus composites - Phase 1

From Figure 13, the average $N_{T}$ as $N_{s}$ varied by $5 \%$ to $200 \%$ was the maximum for CI30 as expected of composites of high cellulose reinforcement and the minimum in CI5, the composite with the minimum content of cellulose reinforcement. The same trend was also observed indicating that varying $N_{s}$ had a similar effect on $N_{T}$ as varying $C$. The average $N_{T}$ when the time of absorption, $T$, varied with $N_{T}$ by $5 \%$ to $200 \%$ was the maximum for CI5 and the minimum for C13 as indicated in the graph for that condition. Composites $\mathrm{C} 13$ and $\mathrm{C} 20$ were found to display the minimum average water absorption while the maximum in $C 130$ for jointly varying $N_{s}$ and $C$. When $T$ and $C$ were varied, the maximum average $N_{T}$ was 1171.94, typical for $C 130$ while the minimum average $N_{T}$ was 127.10 , typical for $C 13$ composite. The maximum average $N_{T}$ of the composites as $N_{s}$ and $T$ varied with $N_{T}$ is 1171.94 which was the value for $C 130$ while the minimum value was found in $C 13$ with the value of 127.10 followed by $C I 20$. The average $N_{T}$ when $C, N_{s}$, and $T$ were varied, showed the maximum value of $N_{T}$ as 668.42 for $C I 5$ and 402.48 as minimum value, which represented value for $C 13$.

e-ISSN: 2289-7771 


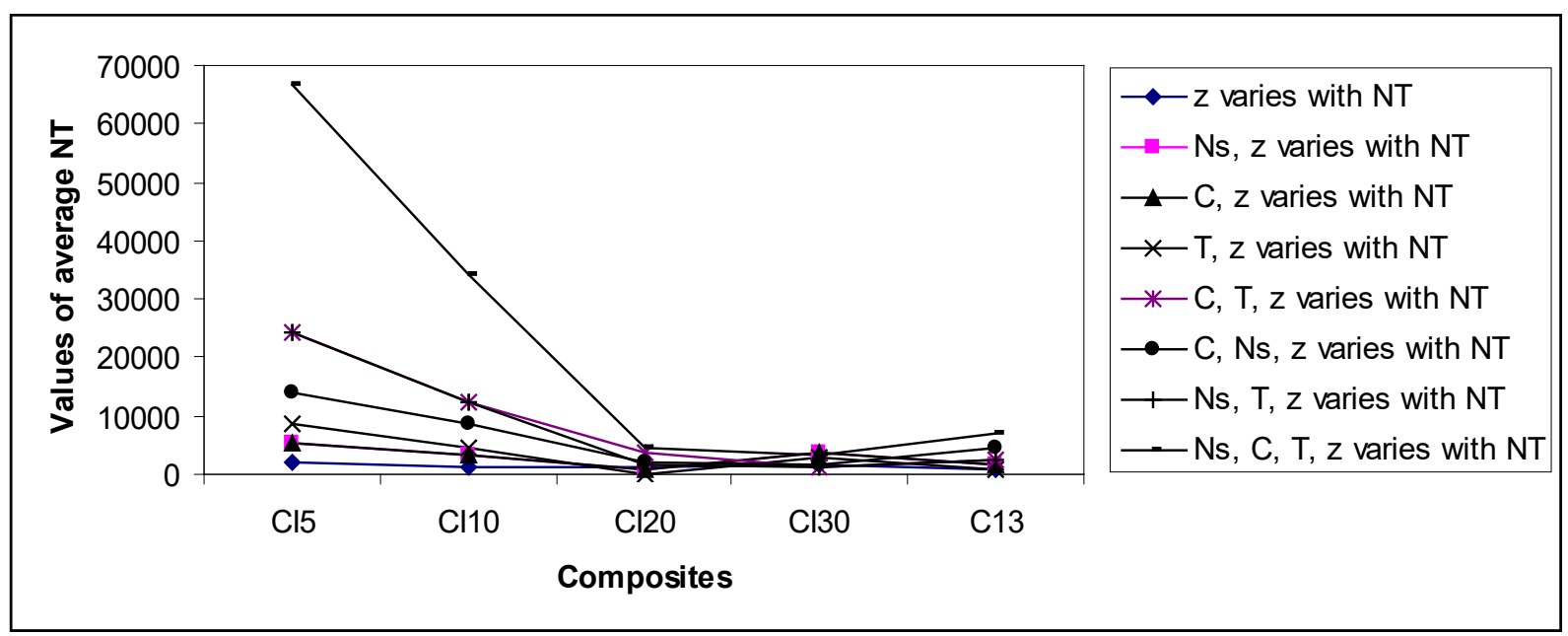

Figure 14. Values of average $N_{T}$ versus composites - Phase 2

The average $N_{T}$ as observed from Figure 14 for a case where the only $Z$ varied by $5 \%$ to $200 \%$ presented the maximum value of $N_{T}$ to be from $C I 5$ while the minimum values were from $C I 10$ and $C I 20$. $C I 5$ had the maximum value of $N_{T}$, which was the result obtained for varying $N_{s}$ and $Z$ with the values 5222.06 and 833.59 for $C I 20$ as minimum followed by $C 13$ with the value 1715.79 . The trend of observation was repeated when $C$ and $Z$ varied with $N_{T}$, proving that varying $C$ and $N_{s}$ had the same influence on $N_{T}$. The average $N_{T}$ when $T$ and $Z$ varied was observed to be the maximum in $C I 5$ and the minimum in $C I 20$ followed by $C 13$. When $C, T$ and $Z$ varied with $N_{T}$, the maximum value of an average $N_{T}$ was 24149.92 for $C I 5$ while the minimum value of average $N_{T}$ was 1273.43 for $C 130$ followed by $C 13$ composite. When $C, N_{s}$, and $Z$ varied, the maximum average $N_{T}$ among the composites was 14020.92 for CI5 while the minimum value was 1761.84 for CI30. When $N_{s}, T$ and $Z$ varied, the maximum average $N_{T}$ was 24149.92 value for $C I 5$ composite and the minimum value of $N_{T}$ was 1273.43 . The value for $C I 30$ was followed by 2554.11 , which represented composite $C 13$. When all the four factors were varied, the maximum value of $N_{T}$ was 66643.84 for $C I 5$ while the minimum value of $N_{T}$ was 3396.11 for $C I 30$ composite.

\subsection{Research findings}

The following findings from the experimental investigation are useful to understand the behaviour of the cocoa pod husk reinforced composite in the water environment:

- The different weight percentages of cocoa pod husk particulate reinforcements in epoxy resin were observed for different variations of $C, Z, T$ and $N_{S}$ with $N_{T}$ of a cylindrical pattern of mould

- All the samples considered for investigation were free of defects and were of the same configuration in diameter and height of the samples above the inner surface of the cylindrical mould

- The reinforcement wt $\%$ composition in the samples was from $1 \mathrm{wt} \%$ to $31 \mathrm{wt} \%$ in steps of $2 \mathrm{wt} \%$

e-ISSN: 2289-7771 
- Investigations were carried out on one factor (i.e. only of $C, Z, T$ and $N_{S}$ varying with $N_{T}$ at a time while others were held constant), two factors, three factors and four factors varying jointly concerning $N_{T}$

- For the sensitivity ranking of $N_{T}$ when only one factor was varied for $13 \%$ cocoa pod husk composite (C13), the most sensitive option was obtained when $N_{S}, c$ and $T$ were constants while z varied with $N_{T}$ as indicated in Table 4a showing how exponential factors could be sensitive to changes

- For the sensitivity ranking of $N_{T}$ when two factors were varied for $C 13$, two options emerged as the most sensitive. The first was when $T$ and $c$ remained constant while Ns and $z$ varied with $N_{T}$. The second instance was when $N_{s}$ and $T$ remained constant while $c$ and $z$ varied with $N_{T}$. This is displayed in Table $4 \mathrm{~b}$, which implied that varying $C$ as the same effect on the $N_{T}$ as varying $N s$.

- For the sensitivity ranking of $N_{T}$ when three factors were varied for $C 13$, the most sensitive option was when $Z$ was constant while $C$, Ns and T varied with $N_{T}$, which is presented in the Table $4 \mathrm{c}$ with increased value of $N_{T}$.

- For the sensitivity ranking of $\mathrm{N}_{\mathrm{T}}$ when four factors were varied for $C 13$, the most sensitive option was when Ns, $C, T$ and $Z$ all varied with $\mathrm{N}_{T}$ presented in Table $4 \mathrm{~d}$

- For the sensitivity ranking of $\mathrm{N}_{\mathrm{T}}$ when only one factor was varied for $C I 5$, the most sensitive option was when $N s, C$ and $T$ were constants while $\mathrm{Z}$ varied with $N_{T}$. This was also true for $C I 10, C I 20$ and $C 130$. This is displayed in Figure 14 confirming the previous claim on $\mathrm{C} 13$ about varying the exponential factor.

- For the sensitivity ranking of $N_{T}$ when two factors were varied for $C I 5$, the most sensitive option was when $T$ and $C$ remained constant while $N s$ and $Z$ varied with $N_{T}$. However, for $C I 10$ involving two factors, $N s$ and $T$ remaining constant while $\mathrm{C}$ and $\mathrm{Z}$ varied with $\mathrm{N}_{\mathrm{T}}$ yielded the most sensitive case. Besides, the option chosen for $C I 20$ and $C I 30$ were the same for $C I 10$ still for the two-factor variation instance (Figures 13 and 14)

- For the sensitivity ranking of $N_{T}$ when three factors were varied for $C I 10$, the most sensitive option was when $C$ was constant while $N s, T$ and $Z$ varied with $N_{T}$. This was also true for $C I 20$ and $C I 30$. However, for $C I 5$, the most sensitive option was when $T$ was constant while $C, N s$ and $Z$ varied with $\mathrm{N}_{\mathrm{T}}$ all indicated in Figure 14

- For the sensitivity ranking of $\mathrm{N}_{\mathrm{T}}$ when four factors were varied for $C I 5$, the most sensitive option was when $N s, C, T$ and $Z$ all varied with $N_{T}$. This was the same for $C I 10, C I 20$ and $C I 30$ as presented in Figure 14

- The sensitivity analysis was wide-ranging, covering $13 \mathrm{wt} \%$ reinforced cocoa pod husk composite for the present study and CI5, CI10,CI20 and CI30 form Imoisili et al. [8]

\subsection{Significance of research findings}

This work suggests a distinctive chance to detail an earlier unreported predictive method, sensitivity analysis, used to weigh the result of water absorption parametric prediction proviso that the water absorption process turns out in a different manner weighed against the principal predictions. The documentation on the $13 \% \mathrm{wt}$ cocoa pod husk composite and its comparison to the $5 \%, 10 \%, 20 \%$ and $30 \%$ wt. cocoa pod husk composite [8] will aid in examining the association of the parameters of water

e-ISSN: 2289-7771

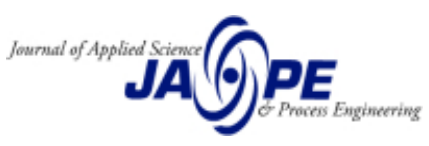


absorption parameters. An analysis of the sensitivity of parameters will permit the use of the experimental design in the analysis of water absorption parameters since it entails combining parameters that would be changed. Thus, the composite designer verifies which and how many parameters ought to vary at any instance of time, mapping values (utmost and least levels) before the experiment and examining the correlations. These interpretations are important to establish the values of the decision variables, and the objective functions.

\subsection{Novelty of this article}

The principal objective of this article is to develop a framework that can help to understand how to measure the degree of responsiveness of water absorption parameters in a saturation process for the cocoa pod husk composite using single and multiple parametric combinations under a linear parametric relationship assumption. Through a growing number of research articles worked on cocoa pod husk composite, very few scholars screened the subject of water absorption process and extremely few have taken experimental samples from the Nigerian geographical area, which may be genetically different in species and behaviour under the water environment and no study has reported on the sensitivity analysis of cocoa pod husk composites. The response of water absorption parameters to the saturation process is the principal motivation to develop water-resistant cocoa pod husk composites. The four principal determinants of water absorption at saturation, namely the absorbed water quantity at saturation and in the time instant, interactive constant and the constant indicating responses between the patterns are taken into consideration and were proved to impact on the water-resistance behaviour of the cocoa pod husk composite. The data obtained in the analysis is extremely important in design decisions during the composite design and development phases.

Imoisili et al. [8] is the closest article to this research in that it addresses the water absorption properties and parameters of cocoa pod husk composite but it is different in focus from the present research principally because it has not considered sensitivity analysis in the study. A common basis of comparison is the composition of the reinforcement used during the fabrication process. While Imoisili et al. [8] used a limited weight addition of particulates in an epoxy matrix as 5, 10, 20 and 30\% filler volume ratio, the current paper takes a superior lead to increase the scope of weight addition from $1 \%$ to $31 \%$ of cocoa pod husk while the steps were decreased to $2 \%$ in a superior order to $5 \%$ reported by Imoisili et al. [8]. This offers the possibility to gain insights into water absorption phenomenon between smaller ranges of variations of reinforcement percentages. Furthermore, there is no standard method to determine the percentage increase with which to vary the parameters while holding others constant for the sensitivity analysis of cocoa pod husk and this report applied a range of $0 \%$ to $200 \%$ in steps of $5 \%$, which is absent in the cocoa pod husk composite literature. This work, therefore, takes a novel approach in the mathematical analysis of sensitivity for cocoa pod husk composite in water environment which has not been reported in Imoisili et al. [8] and other previous papers on cocoa pod husk composites. The information provided by Imoisili et al. [8] is sufficient for a deep understanding of the curing period of the composite. However, as mentioned in this paper as 76 hours, a frontline standard is set for other papers with which comparison could be made and this novel step distinguishes the current study from others. Besides, the source of reinforcement for the current study was a farm settlement in the southern part of Kwara State, Nigeria whereas the samples collected by Imoisili et al. [8] were around the Akure area.

e-ISSN: 2289-7771

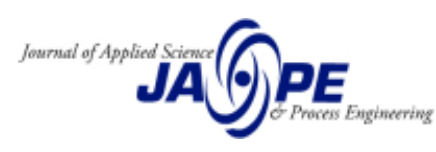




\section{Conclusion}

In this study, the sensitivity analysis of the important water absorption parameters of cocoa pod husk composites at saturation was examined. The work analysed the water absorption parameters by adopting the popular technique of the least square equation and fitting the four parameters of water absorption at saturation, namely the absorbed water quantity at saturation and in the time instant, interactive constant and the constant indicating responses between the patterns into it. Each parameter was varied while others were held constant at the same time in a system where single and joint interactions of parameters were considered. After examining the results of a laboratory experiment where the fabrication of the composites was done with varying weight fraction contents of reinforcement varying from 1 to $31 \%$ in steps of $2 \%$, the sensitivity analysis concluded that for a single factor variation, the best option based on the ranking was when the constant indicating responses varied with absorbed water quantity in time while other parameters were held constant. The worst rank was obtained when time varied with absorbed water quantity in time. For two-factor variations, the best options were a tie between when the constant indicating responses varied with absorbed water quantity in time while other parameters were constant. The worst-case was observed with when time varied with the constant indicating responses. For the three-factor situation, the best and worst ranks were when time varied with absorbed water quality in time (best) and when time varied with the constant indicating responses (worst). For the four-factor variation, the results were that the parameters were very sensitive to changes.

Although previous reports were limited to water absorption, this study is the first to report on sensitivity analysis of water absorption parameters for cocoa pod husk composites. The results may vary if non-linear quadratic functions and other mathematical behaviour functions are used for modeling over the same period of analysis. Future researchers may consider studying the effect of variations in the power of the terms on the outcomes. This study advances knowledge on the parametric behaviour of water absorption process at saturation for cocoa pod husk composite as it addresses how these parameters may be tested under the situation of parametric responsiveness to changes while singular and multiple parameters are considered. It points out that at $13 \%$ volume fraction of cocoa pod husk reinforced composites and the consideration of single and multiple parametric changes, certain parameters are the least and most sensitive and the ranking of the cases within the broad classification aspect is possible by considering the sum, average and ratios of the individual parametric changed in the water absorption process evaluation. Thus scientific evidence is provided to prove that certain parameters are more responsive to changes than others. The use of simple statistical measures is to appeal to institutional researchers and composite designers to become more interested in adopting a practical yet effective approach to determining the responsiveness of important water absorption parameters in the saturation process of cocoa pod husk composite water absorption study. Furthermore, composite designers may apply the results of the study for planning and predictive purposes. 


\section{Appendix}

Table A. Specific regression equations on defined immersion dates using $\log N_{T} / N_{s}=\log C+Z \log T$

\begin{tabular}{llll}
\hline & & Immersion: 21 days & Immersion: 31 days \\
\hline S/No. & $\begin{array}{l}\text { Particulate } \\
\text { Loading }\end{array}$ & Regression equation & Regression equation \\
\hline 1 & $1 \%$ & $0.153948514=\log C+4.480582 \mathrm{z}$ & $0.048605333=\log C+4.649724 \mathrm{z}$ \\
2 & $3 \%$ & $-0.072382336=\log C+4.480582 \mathrm{z}$ & $-0.051557837=\log \mathrm{C}+4.649724 \mathrm{z}$ \\
3 & $5 \%$ & $0.020566357=\log \mathrm{C}+4.480582 \mathrm{z}$ & $0.007916109=\log \mathrm{C}+4.649724 \mathrm{z}$ \\
4 & $7 \%$ & $-0.065785574=\log \mathrm{C}+4.480582 \mathrm{z}$ & $0.073990559=\log \mathrm{C}+4.649724 \mathrm{z}$ \\
5 & $9 \%$ & $-0.086930291=\log \mathrm{C}+4.480582 \mathrm{z}$ & $0.011717288=\log \mathrm{C}+4.649724 \mathrm{z}$ \\
6 & $11 \%$ & $-0.055348637=\log \mathrm{C}+4.480582 \mathrm{z}$ & $0.039024108=\log \mathrm{C}+4.649724 \mathrm{z}$ \\
7 & $13 \%$ & $-0.004885254=\log \mathrm{C}+4.480582 \mathrm{z}$ & $0.02086532=\log \mathrm{C}+4.649724 \mathrm{z}$ \\
8 & $15 \%$ & $-0.296741256=\log \mathrm{C}+4.480582 \mathrm{z}$ & $-0.182604841=\log \mathrm{C}+4.649724 \mathrm{z}$ \\
9 & $17 \%$ & $-0.107775089=\log \mathrm{C}+4.480582 \mathrm{z}$ & $0.001690961=\log \mathrm{C}+4.649724 \mathrm{z}$ \\
10 & $19 \%$ & $-0.296758849=\log \mathrm{C}+4.480582 \mathrm{z}$ & $-0.117076239=\log \mathrm{C}+4.649724 \mathrm{z}$ \\
11 & $21 \%$ & $-0.099461604=\log \mathrm{C}+4.480582 \mathrm{z}$ & $-0.007852548=\log \mathrm{C}+4.649724 \mathrm{z}$ \\
12 & $23 \%$ & $-0.076337306=\log \mathrm{C}+4.480582 \mathrm{z}$ & $-0.000823174=\log \mathrm{C}+4.649724 \mathrm{z}$ \\
13 & $25 \%$ & $-0.076028979=\log \mathrm{C}+4.480582 \mathrm{z}$ & $-0.064199215=\log \mathrm{C}+4.649724 \mathrm{z}$ \\
14 & $27 \%$ & $-0.095448388=\log \mathrm{C}+4.480582 \mathrm{z}$ & $-0.029655104=\log \mathrm{C}+4.649724 \mathrm{z}$ \\
15 & $29 \%$ & $-0.057586632=\log \mathrm{C}+4.480582 \mathrm{z}$ & $0.087150176=\log \mathrm{C}+4.649724 \mathrm{z}$ \\
16 & $29 \%$ & $-0.07702368=\log \mathrm{C}+4.480582 \mathrm{z}$ & $-0.027308343=\log \mathrm{C}+4.649724 \mathrm{z}$ \\
17 & Control & $-0.098008103=\log \mathrm{C}+4.480582 \mathrm{z}$ & $0.072550667=\log \mathrm{C}+4.649724 \mathrm{z}$ \\
\hline
\end{tabular}

\section{References}

[1] Shahzad, A. (2012). Effects of water absorption on mechanical properties of hemp fiber composites. Polymer Composites, 33(1), 120-128.

[2] Zahari W.Z,W, Badri; R.N.R.L Ardyananta H. , Kurniwan D., Nar F.M. (2015). Mechanical properties and water absorption behaviour of polypropylene/ijuk fibre composite by using silane treatment, Procedia Manufacturing, Vol. 2, 573-578

[3] Ma G., Yan L., Shen W, Shen W, Zhu D., Huang L., Kasal B. (2018) Effects of water, alkali solution and temperature aging on water absorption morphology and mechanical properties of natural FRP composites: Plant - based Jute Vs Mineral - based basalt, Composite Part B, Vol. 153, 396 - 412

[4] Peret T., Clement A. Freour S., Jacquemin F. (2019) Homogenization or Fickian and non-fickian water diffusion in composites reinforced by hydrophobic long fibres: application to the determination of transverse diffusivity, Composite Structures, Vol. 226, 1-9.

[5] Sahore A.D., AfferiJ.K., Oka L., Abouattier J.L., Boua K.B. (2015) Contribution to the study of cocoa pod cortex volarisation, Journal of Global Biosciences, Vol. 4, No. 8, 3201-3206

[6] Imoisili P.E., Ezenwafor T.C., Attah-Daniel B.E., and Olusunle S.O.O., (2013), Mechanical properties of cocoa-pod epoxy composite: Effect of filler fraction, American Chemical Science Journal, Vol. 3, No. 4, 526-531

[7] Imoisili PE, Etiobho BW, Ezenwafor TC, Attah-Daniels BE, Olusunle Soo. (2013). Physicochemical analysis of cocoa pod and its effect as a filler in polymer resin composite, International Journal of Science and Technology, Vol. 2, No. 1, 89-93

e-ISSN: 2289-7771

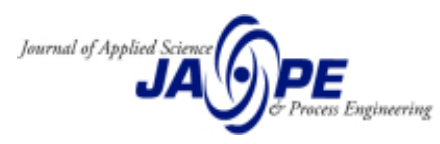


[8] Imoisili P.E., Jiddah-Kazeem B., Yahaya L.E. (2016). Kinetic studies on water absorption properties of cocoa-pod epoxy composites, Iranian Journal of Energy and Environment, Vol. 7, No. $1,48-51$

[9] Chun KS and Husseinyah S. (2016) Agrowaste-based composite from cocoa pod husk and polypropylene: Effect of filler content and chemical treatment, Journal of Thermo-plastic Composite Materials, Vol. 29, No. 10, 1332-1351

[10] Chun KS, Husseinsyah S and Yeng CM. (2017.), Torgue rheological properties of polypropylene/cocoa pod husk composites, Journal of Thermoplastic Composite Materials, Vol. 30, No. 9, 1217-1227

[11] Chun KS, Husseinsyah S and Osman H, (2015). Utilization of cocoa pod husk as filler in polypropylene biocomposite: Effect of maleated polypropylene, Journal of Thermoplastic Composite Material, Vol. 28, No. 11, 1507-1521

[12] Chun KS, Husseinsyah S, Osman H. (2014). Development of biocomposites from cocoa pod husk and polypropylene: Effect of filler content and 3-Aminopropy/triethoxy/silarre, Polymers and Renewable Resources, Vol. 5, No. 4, 139-156

[13] Olabisi AI, Adam AN, Okechukwu OM. (2016) Development and assessment of composite brake pad using pulverized cocoa bean shells filler, International Journal of Materials Science and Applications, Vol. 5, No. 2, 66 -78

[14] Liu Q. and Paavola J. (2018). General analytical sensitivity analysis of composite laminated plates and shells for classical and first-order shear deformation theories, Composite Structures, Vol. 183: 21-34

[15] Thakur S.N., Ray C., Chakraborty S. (2018). Response sensitivity analysis of laminated composite shells based on higher-order shear deformation theory, Vol. 88, No. 8, 1429 - 1459

[16] Akash, Arunkumar D.S., Gupta N.S.V., Rao K.V.S. (2017). Effect of samanea saman pod pulp on mechanical and water absorption properties of bio-composites. Materials Today: Proceedings, Vol. 4, No. 9, 9592-9596

[17] Hosseinaei O. , Wang S. Taylor A.M, Kim J. (2012). effect of hemicellulose extraction on water absorption and mold susceptibility of wood-plastic composites, International Bio-deterioration and Biodegradation, Vol. 71, 29-35

[18] Anjang A., Chevail V.S., Feih S., Mourit A.P. (2016). Deterioration of the fire structural resistance of sandwich composite under tension due to water absorption, Composite: Part A, Vol. 87, 263-270

[19] Khan A., Tyagi P., Papu A., 2019, Epoxy poly pyrrole-straw composites: Towards higher detective constant and lower water absorption, Materials Letters, Vol. 254: 262-265

[20] Ngaowthong C., Boruvka M., Bahaleh L., Lenpel P., Svec M., Daugtungee R., Siengchin S., Raugappa S. M., Parameswaranpillai J. (2019). Recycling of sisal fibre reinforced polypropylene and polylactic acid composites: Thermo mechanical properties, morphology, and water absorption behaviour, Waste Management, Vol. 97, 71-81

[21] Arputhabalan J., Palanikumar K, Adaikalaraj S. , Sugar P.M. (2019). Investigation of glass fibre influence on mechanical characteristics and resistance to water absorption of natural fibre reinforced polyester composites, Materials Today: Proceedings, Vol. 16, 843-852

[22] Bahra MS, Gupta VK, Aggarwal L. (2017). Effect of fibre content on mechanical properties and water absorption behaviour of pineapple/HDPE composite. Materials Today: Proceeding, Vol. 4, No. 2, 3207-3214.

[23] Tian F, Zhong Z. (2019). Modeling of load responses for natural fibre reinforced composites under water absorption, Composites Part A, Vol. 125, 105564.

e-ISSN: 2289-7771

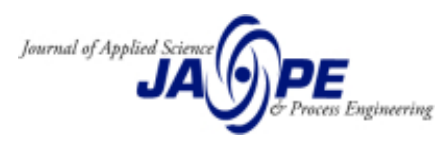


[24] Mishra D., Mohapatra S., Satapathy A. (2019) A comparative study of characterization and water absorption behaviour of polyester composites with inorganic and organic fibres, Materials Today: Proceedings, Vol. 19, No. 2, 289-295.

[25] Rajesh G. Prasad A.V.R., Gupta A.V.S.S.K.S. (2018). Water absorption characteristics of Successive alkali treated Jute/Ploylacticacid composites, Materials Today: Proceedings, Vol. 5, 24414-24421

[26] Dayo A.Q, Zegaoui A., Nizamani A.A., Kiran S., Wang HJ., Deraji M., Cai W., Liu W. (2018). The influence of different chemical treatments on the hemp fibre/polybenzoxozine based green composites. Mechanical, thermal and water absorption properties, Materials Chemistry and Physics, Vol. 217, 270-277.

[27] Devani G.L., Mital V., Sinha S. (2018). Mathematical modeling of water absorption behaviour of bagasse fibre reinforced epoxy composite material, Materials Today: Proceedings, Vol. 5, 1691216918

[28] Selvam R., Ravi S., Raja R. (2018). Wear resistance and water absorption study of SiC reinforced polyester composite, Materials Today: Proceedings, Vol. 5: 14567-14582.

[29] Radzi A. M., Sapuan S.M., Jawaid M, Mansor M.R. (2019). Water absorption, thickness, swelling and thermal properties of roselle/sugar palm fibre reinforced thermoplastic polyurethane hybrid composites, Journal of Material Research and Technology, Vol. 8, No. 5, 3988-3994.

[30] Chellamuthu K., Vasanthanathan A. (2019). Experimental analysis of GFRP with PET for intensive load and water absorption, Materials Today: Proceedings, Vol. 21, 658-662. https:idoi.org/10.1016/j.matpr.2019.06.734

[31] Ajibade O.A., Agunsoye J.O., Oke S.A. (2017). An assessment of water absorption properties of orange peel particulate-based epoxy composite by optimisation.Engineering and Applied Science Research, Vol. 44, No. 3, 129-141.

[32] Ajibade O.A., Agunsoye J.O., Oke S.A. (2019). Optimisation of water absorption parameters of dual-filler filled composites using Taguchi and moderated Taguchi techniques, Kufa Journal of Engineering, Vol. 10, No. 2, 134-151

[33] Bujjibabu G., Das V.C, Ramakrishna M, Magarjuna (2018). Mechanical and water behaviours natural fibres reinforced polypropylene hybrid composites, Materials Today: Proceeding, Vol. 5, 12249-12256.

[34] Jane H., Pradhan A.K, Pandit M.K. (2014). Studies on water absorption behaviours of bambooepoxy composite filled with cenosphere, Journal of Reinforced Plastic and Composite, Vol. 33(11): 1059-1068

[35] Siddiqui M.A. (1997). Economic analyses of absorption systems: Part B - Optimisation of operating parameters, Energy Conversion and Management, Vol. 38, No. 9, 905-918

e-ISSN: 2289-7771

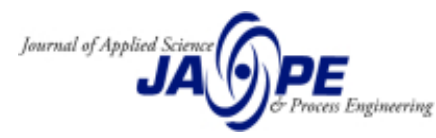

